\title{
Perspective
}

\section{A Brief Philosophical Encounter with Science and Medicine}

\author{
Amir Ehsan Karbasizadeh* \\ Iranian Institute of Philosophy (IRIP), Tehran, Iran
}

Received: 18 June 2013, Accepted: 21 July 2013, ePublished: 25 July 2013

\begin{abstract}
We show a lot of respect for science today. To back up our claims, we tend to appeal to scientific methods. It seems that we all agree that these methods are effective for gaining the truth. We can ask why science has its special status as a supplier of knowledge about our external world and our bodies. Of course, one should not always trust what scientists say. Nonetheless, epistemological justification of scientific claims is really a big project for philosophers of science. Philosophers of science are interested in knowing how science proves what it does claim and why it gives us good reasons to take these claims seriously. These questions are epistemological questions. Epistemology is a branch of philosophy which deals with knowledge claims and justification. Besides epistemological questions, metaphysical and ethical issues in science are worthy of philosophical scrutiny. This paper gives a short survey of these intellectually demanding issues.
\end{abstract}

Keywords

Philosophy, Medicine, Science

$\mathrm{I}$ $\mathrm{t}$ seems obvious that any interesting scientific hypothesis has implications whose truth cannot be established by direct observation. This may be because the hypothesis has implications for what goes on at distant locations, or in the future or for any other reasons. There is thus little hope that we will be able to simply deduce the truth of scientific hypotheses and theories from observations in the way that conclusions can be deduced from their premises in logic. This claim is supported by the history of science, which tells us that even the bestconfirmed theories (such as Newtonian gravitational theory) can be undermined by further evidence. Thus, while fields such as mathematics and logic trade in certainties; scientific hypotheses always remain at least partly conjectural (1).

In light of this situation, some philosophers have attempted to apply the concepts of probability to scientific theories and hypotheses. While it may be impossible to establish a scientific hypothesis with certainty, a hypothesis may be rendered more or less probable in light of evidence. Evidence that increases the probability of a theory is said to support or confirm that theory, while evidence that lowers the probability of a theory is said to undermine or disconfirm it. One of the reasons why there is a gap between observational evidence and scientific theory is that the latter often makes claims about entities that are unobservable.
Are scientific claims about unobservable entities especially problematic? Questions of this sort are central to millennia-old debates between realism and anti-realism. Confirmation and the relation of theory and evidence are not the only philosophical problems that arise from science. Scientists try to explain natural phenomena and philosophers try to understand how scientist explain things.

Consider the following story ${ }^{1}$.

A large cancerous tumour was removed from a 51 year old man in 1956 in a Massachusetts hospital and accordingly he was diagnosed with a number of other tumours-all inoperable. His case was filed away and he was sent home to die. Surprisingly, the same man, twelve years later, showed up in the emergency room of the same hospital with an swollen gallbladder. Some doctors concluded that the original diagnosis had been false and think no more of it, Steven Rosenberg, a young surgeon, was not like his colleagues. Having searched all the related hospital records, Rosenberg found the original tissue slides of the patient's removed tumour and reexamined them. The slides showed that an aggressively malignant tumour had been removed from the man in the first operation and it was almost certain that the inoperable ones had been of the same aggressively malignant type. During the subsequent operation to remove the patient's gallbladder Rosenberg explored the man's abdomen to see if the inoperable tumours from twelve years earlier had stopped growing. The man had no tumours at all in the places his record from twelve years earlier located them.

To Rosenberg, the man whose gallbladder he had removed presented a mystery. How had a patient with multiple inoperable cancerous tumours survived for twelve years in the apparent absence of any therapy whatsoever? Such "spontaneous remissions" have not been unheard of in medicine-they have long been a central obsession of fashionable occultists and other kinds of healers-but Rosenberg wanted to know the detailed why of it.

Rosenberg looked for an explanation of spontaneous remission in perfectly natural terms. He wanted to know how a physiological processes-i.e. the immune system of the human body could produce such a remission. Rosenberg carried on the assumption that there had to be some structural physiological basis behind the patient's remission and survival for twelve

\footnotetext{
1. This example is taken from Klee, 1997 (1)
}

${ }^{*}$ Corresponding author: Amir Ehsan Karbasizadeh; Email: amir_karbasi@yahoo.com 
years, a structural physiological basis that was consistent with the otherwise ordinary causal operations of the human body. Rosenberg was looking after the causal details of that structural physiological basis.

If he could find out those details, especially if they were quantitative details, then the possibility of being able to manipulate the physiology of cancer patients emerges.

Finally, not only did he find an explanation in perfectly natural terms for the original patient's spontaneous remission, but using the theoretical account of immunological processes associated with that explanation he was able to design a complicated treatment involving artificially growing cancer killing immune cells outside the body. These cancer-killing immune cells, called lymphokine activated killer (LAK) cells, are injected back into the patient's body in an attempt to intervene and manipulate the patient's immune response to the cancer. Rosenberg and his colleagues have had a considerable degree of success at producing remissions with this therapy but only for specific kinds of cancer-particularly, kidney cancer and skin cancer. Apparently, knowledge of further structural detail is needed in order to be able to design LAK cells that are effective in other kinds of solid-tumor cancers.

The preceding case illustrates the important point that science involves a practical engagement with the natural world. This point is often lost sight of when science is portrayed by both its supporters and critics as a largely intellectual enterprise, as a game consisting mostly of free-form conceptual speculation. The process through which science produces knowledge is more constrained than that, and it is messier in the bargain.

Rosenberg desired a scientific explanation of what was experimentally and observationally unquestionable-the spontaneous remission of his gallbladder patient's previous cancer. Most philosophers take explanation to be the main business of science. They spend much of their time to study some account or other of scientific explanation-what it requires and how it differs from other kinds of explanation in other realms.

In the situation in which Rosenberg found himself, if anything, there were too many alternative explanations $(1,2)$. Theories go far beyond the data that support them; indeed, the theories would be of little interest if this were not so. However, this means that a scientific theory is always 'underdetermined' by the available data. Even if there were no anomaly in sight, so the theory is compatible with all known data, it is impossible to deduce or prove the theory from them. This means that there always exists, in principle, incompatible theories that also would have fit those data.

For now, it might be instructive to consider what Steven Rosenberg did in the face of the underdetermination of theory. His task was to pare down the number of competing possible theoretical explanations for his patient's spontaneous remission in a rationally defensible way-in an evidence based way and not in an arbitrary way. He used the finely detailed causal structure in the human immune system to do so; and, in that way, he let the independent causal structure of the world push back against his own hypothesizing to do the paring down. Thus, Rosenberg's general procedure was evidence driven in a way that, say, theological speculation and political rhetoric are not. The latter two practices are not forms of knowledge gathering primarily driven forward and constrained by independent causal evidence. Another big project for philosophers of science is metaphysical questions about science. Scientists often talk about laws. In our story, there seems to be laws governing LAK cells behaviour regarding kidney tumours. Modern science, especially modern physics, is often described as a search for, among other things, the laws of nature. Few physicists claim that we have any of the actual laws of nature at hand, but nonetheless it is often said that we are closing in on these laws. Moreover, the major theories of modern physics, including classical mechanics, classical thermodynamics, quantum mechanics and general relativity, are all usually interpreted as proposing sets of laws. Many other scientific theories put forward principles or equations that are designed as laws. All of this shows that the concept of laws of nature is a central one for modern science or at least that scientists often take it to be. So what makes something a law? Philosophers want to know what it is to be a law of nature (3).

Scientific talk is infused with causal terms. Remember Rosenberg's story. LAK cells were injected because they were causally effective in preventing the cancer. Philosophers of science are eager know what constitutes causal relations in science. The nature of causation is philosophically controversial (4). Some philosophers, following the empiricist approach of Hume, think that, even as it occurs in particular cases, causation is to be understood in terms of the holding of something more general, so that for one item to cause another is, or is partly, a matter of there being some law or regularity concerning the sequential occurrence of items of those types. Other philosophers think that causation is something irreducibly singular, so that when one item causes another, that is not to do with how things behave or are constrained in general, but is purely to do with how things stand with respect to those particular items.

Philosophers of science never seem to settle their own arguments and, in so far as their argument yields any result, it is one of generalized agnosticism that is not a live option for scientists. One might go so far as to worry that if philosophy did have any impact on scientists, it would be pernicious, depriving them of the kinds of commitment and confidence upon which their practice depends. However there are few scientists who want to understand how science works and it is natural for them to wish to turn this curiosity back on themselves, and so to wish to understand how their own enterprise works. This is why they may find philosophy of science worth pursuing.

\section{Philosophy of medicine}

Medicine is an interesting case study for philosophers of science. However, philosophers tended to ignore it until 1960. At the end of the 1960's, conferences had begun to recognize puzzles of a philosophical sort about medicine. There was a cultural appetite to locate medicine within larger cultural contexts. The discipline represented vividly interplay of values, institutions, science, technology, economic forces and most importantly human interaction of patients and physicians. The appetite was driven by the increasing popularity and achievements of medicine itself. In every developed country, health care was claiming a larger portion of the gross domestic product. The promise of new technologies also threatened apparently novel moral and public policy puzzles.

If physics deserved a philosophy of physics, medicine seemed to deserve something like a philosophy of medicine. Although that term was hardly used in the 1960's philosophy of medicine had a history that reached to the beginning of the 19th century (5). The first philosophical debates focused on the question of scientific status of medicine. Is medicine a science? It seems almost banal not to identify medicine with biology. The former involves close cooperation and interaction of doctor and 
patient, an extremely vital feature the latter lacks. Based on this observation, some philosophers have argued that medicine should be best envisaged as a social science (6).

Critical care units and organ transplantation, like other new technologies used in medicine, pressed for clarity about issues such as determining when death occurs. Old ethical problems became more pressing because these new technologies had become safer and more tempting: for instance, abortion became associated with fewer risks of mortality, and there was the promise of ever more effective prenatal diagnosis and selective destruction of fetuses. Moreover, there appeared to be purely philosophical issues such as the nature of disease and illness that were addressed by neither the philosophy of medicine nor even the philosophy of biology. Are disease natural features of the world? Should we be realist about diseases or there are just social conventions? There were these and many other issues of evaluation of evidence, epistemological questions, and explanation associated with medicine that have since given birth to sustained philosophical reflection and analysis. Three decades ago, few philosophers seemed to notice them. Or if they noticed them, they were not yet sure how to name them or whether to place them within an independent field.

For instance, it is widely believed that medical results and evidence should be obtained via randomized controlled experiments. This very sentence needs much of philosophical clarifications. At a close inspection, it turns out that medical practice has always been based on elusive and plural notions of evidence, such as clues and symptoms, but what should be counted as evidence has changed over time. For instance, effectiveness of treatments was once judged on the basis of a complex mix of theory, clinical observation and testimony, but as case descriptions (and treatments) became more standardized and comparisons could be made, assessment of effectiveness moved beyond the single cases and case series, and adopted the population as the unit of assessment and analysis. The Randomized Controlled Trial (RCT), and meta-analyses thereof, have become the primary means by which medical interventions (particularly pharmaceutical interventions) are deemed effective and worthy of funding. Given the power accorded to the RCT (philosophers call it as the "gold standard" of medical research) there is a growing tendency to subject epistemology of RCT to rigorous scrutiny (7).

Above mentioned problems have shaped what we call philosophy of medicine, an independent and growing area of philosophy in recent years.

Ethical issues

Not applicable.

Competing interests

The author declares no competing interests.

Author's contribution

AEK is the single author of the manuscript.

References

1. Klee R. Introduction to the Philosophy of Science-Cutting Nature at Its Seams. New York: Oxford University Press; 1997.

2. Ladyman J. Understanding Philosophy of Science. London: Routledge; 2002.

3. Bird A. Philosophy of science. London: Routledge; 1998.

4. Sosa E, Tooley M. Causation. London: Oxford University Press; 1993.

5. Engelhardt HT. The Philosophy of Medicine: Framing the Field. London: Springer; 2011.

6. Kenneth F, Schaffner KF, Salmon WC, Norton JD, McGuire JE, Machamer $\mathrm{P}$, et al. Introduction to the philosophy of science. $1^{\text {th }}$ ed. Indianapolis: Hackett Publishing Co, Inc; 1999.

7. Bresalier M. History and philosophy of Medicine: Unit Guide. Univerity of Bristol; 2006. 